\title{
MOBILE TECHNOLOGY AFFECTING TEACHING AND LEARNING IN RURAL SCHOOLS
}

\author{
Marlien Herselman ${ }^{1,2}$, Adele Botha ${ }^{1,2}$, Keneilwe Maremi $^{1,2}$, Sifiso Dlamini $^{1}$ and Mario Marais ${ }^{1}$ \\ ${ }^{I}$ CSIR, P.O. Box 395, Pretoria, South Africa \\ ${ }^{2}$ University of South Africa, School of Computing, Florida Campus, South Africa
}

\begin{abstract}
The purpose of this paper is to provide monitoring and evaluation results of how teaching and learning were affected in 24 rural schools in 7 provinces of South Africa after a three-year mobile technology implementation project. Teachers face many challenges in rural schools as access to the Internet, electricity, basic amenities and training to use technology in the classroom are often not attained. Large classes and unsupportive principals can also influence the sustainable use of mobile technology in these schools. Two theories of change (implementation success and improved quality of teaching and learning) were applied through an End-line survey to determine how the Information Communication Technology for Education (ICT4E) project, affected teaching and learning in the selected rural schools. Funded by the Department of Agriculture and Rural Development (DARD) in South Africa, the Council for Scientific and Industrial Research (CSIR), Pretoria campus was mandated to implement the project. The implementation involved providing mobile tablets to all teachers, and schools, training the teachers through a university accredited Teaching Professional Development (TPD) course, training 48 ICT Technicians to support teachers and doing a baseline and end-line survey. At the end of the project, 184 teachers successfully completed the TPD training and 6895 learners were affected. The methodology that was applied is a sequential explanatory mixed-method approach where data was collected using firstly a survey, followed by one-to-one interviews. Data were analyzed using descriptive statistics (quantitative data) as well as coding through Nvivo (qualitative data). The main results indicated that $97 \%$ of the teachers will continue to use mobile technology for teaching rather than traditional teaching. The teachers also indicated that for them the most outstanding benefit of the TPD was to learn new teaching strategies. Teachers reported an $80 \%$ improvement in school attendance and that learners were much more involved and eager to learn when using mobile tablets in the schools. Teachers continued to develop their own communities of practice to share lesson plans and ideas in specific subjects (Mathematics and Science). The project, therefore, had a very positive affect on teaching and learning and was statistically proven to be a success.
\end{abstract}

\section{KEYWORDS}

Monitoring and Evaluation, Teaching and Learning, Mobile Tablets, Teacher Professional Development, Rural Schools

\section{INTRODUCTION}

The Council for Scientific and Industrial Research (CSIR) in Pretoria, South Africa, was mandated by the Department of Agriculture and Rural Development (DARD) to implement the ICT for Education Project (ICT4E) over a period of three years (2017-2019). The overarching objective of the mobile technology project was to improve the quality of teaching and learning in a rural context through the introduction of proven technologies, frameworks and approaches that have been tested, creating an enhanced teaching and learning process.

The purpose of the project's monitoring and evaluation function was to contribute evidence (through surveys) that informed the responsive evolution of ICT4E's implementation; and also to compile evidence that would inform the design and implementation of similar projects in future (Herselman, Botha \& Maremi, 2019). The DARD selected 24 schools in 7 provinces of South Africa (Gauteng, Eastern Cape, Free State, Northwest, Northern Cape, Kwa-Zulu Natal and Limpopo) and the principals of the selected schools had to identify 10 suitable teachers who received Teacher Professional Development through accredited training materials. The IDEAS Lab at the University of the Free State won the open tender process to facilitate all training of teachers and two selected youths from the respective community where the school is situated who should provide technical support to the teachers (Dlamini \& van der Vyver, 2019). 
For the purpose of this paper, the focus will be on sharing the monitoring and evaluation results of the End-line survey results that were applied after the training over a period of two years. These results will reflect the difference this project has made on the teaching and learning in these schools.

Rural schools in South Africa are struggling to implement the White Paper on e-education (Department of Basic Education, 2004), especially at the organizational level (Kotzé, Van der Westhuizen \& Barnard, 2017; Vandeyar, 2010). The reason for this relates to contextual issues, lack of resources and infrastructure as well as the ability to translate the country's national policies to provincial policies.

The research question of this paper is: What evidence was found to indicate implementation success and improved quality of teaching and learning when mobile technology was used in training teachers in selected rural schools in South Africa? This will be addressed in the results section.

The focus is specifically on rural schools in resource-constrained environments where low-income communities reside and power as well as bandwidth are challenges (Botha \& Herselman, 2018). Other constraints in this type of context can include cultural issues and people are usually not familiar with or have the anxiety to use technology (Adukaite, van Zyl, Er \& Cantoni, 2017).

\section{CHALLENGES FACED BY TEACHERS WHEN USING TECHNOLOGY TO TEACH}

There is an expectation that all teachers should have $21^{\text {st }}$-century skills to teach with technology to enhance their teaching practice (Botha, Herselman, Musgrave \& Jaeschke, 2017). Vosloo (2011) however indicates that investments in technology should rather be channeled towards training teachers to use these technologies effectively. Investing time and money to improve teachers, and teaching, is viewed by members of School Governing Bodies (SGBs) as pivotal (Botha et al., 2017). For this to happen teachers have to be trained to apply and develop the content of a digital nature and to use technology in their specific subject areas (Ekanayake \& Wishart, 2014).

Apart from TPD training, the teacher has to be seen as part of a system and their attitudes, beliefs and anxiety levels, when integrating mobile technology into their classrooms, are essential to respect (Dagdilelis, 2018). Anxiety can be overcome if teachers can learn new skills to use the technology to support their teachning to enhance classroom practices and learn from their fellow colleagues (Scherer, Siddiq \& Tondeur, 2019; Chiu \& Churchill, 2016; Jantjies \& Joy, 2016; Teo, Lee \& Chai, 2008).

Thoughtfulness, creativity, and commitment to sustain specific action plans are required to successfully integrate technology to support teaching (Naiman, 2016). Successful integration of mobile technology to support collaborative learning has also been indicated by Fu and Hwang (2018) and explained by Hwang, Chu and Lai (2017) when a mobile learning project was conducted in Taiwan. Training teachers to use applications during their teaching can enhance their own skills and also influence the learning of their learners (Adukaite et al., 2017). Teachers should also consider creating learning communities of practice amongst themselves to support their own development and to enhance their $21^{\text {st }}$-century skills development (Karam, Straus, Byers, Kase \& Cefalu, 2018). Even if there are concerns about the integration of technology into educational settings (Bates, Swennen \& Jones, 2014), it is believed that with the support of adequate leadership and the potential of digital content to support teaching, these challenges can be counteracted (Terhoven \& Fataar, 2018; Rikkerink, Verbeeten, Simons \& Ritzen, 2016).

In order to eliminate poverty, reduce inequality and spur economic development, South Africa's National Development Plan (NDP) identifies education, training, life-long learning and innovation as key priorities (National Planning Commission, 2012). As is indicated by Mabila, Van Biljon and Herselman (2017) there are four major features supported by the E-education policy framework for the use of ICT in teaching and learning in South Africa which is: equity, access to ICT infrastructure, capacity building and norms and standards. Education systems must change to facilitate mobile access to education and one of the most important changes is training teachers to prepare them for the mobile world (Ally, 2009). The infrastructure of a school also affects the sustainable use of mobile technology, as some schools, especially in rural areas of South Africa lack basic equipment like desks and many computer facilities at these schools are under-serviced and dysfunctional (Terhoven \& Fataar, 2018). Better qualified teachers move to better-equipped schools where there is adequate infrastructure, buildings, electricity, lavatories, learning materials, and resources, as these factors directly affect teachers' and learners' performances (Ramorola, 2018). 
The challenges of the educational school system in South Africa should not be underestimated as conditions in which teachers work are complex due to the pervasive legacies of South Africa's history (Ramorola, 2018). The subsequent changes in policies and implementation that have occurred since the dawn of democracy in 1994, did result in different education departments (Mabila et al., 2017). However, teachers have had to cope with the changes amid other challenges, as new curricula have been introduced (Terhoven \& Fataar, 2018). Teachers, therefore, face many challenges in schools in South Africa (Ramorola, 2018).

Therefore in order to counteract these challenges, the DARD with the CSIR decided to invest in these communities throughout South Africa by providing infrastructure and training to teachers to use the infrastructure (mobile tablets, servers, and learner tablets) more effectively.

\section{THE SCOPE OF THE ICT4E PROJECT IS TO SUPPORT TEACHING AND LEARNING IN RURAL SCHOOLS}

The scope of the ICT4E Project was to deploy ICT infrastructure to 24 beneficiary schools, to design, develop and accredited training material for use during the project, to provide teacher professional development (TPD) training and accreditation, and to training School ICT technicians (two for each school to support teachers with technical issues.

The implementation model, therefore, involved the deployment of tablets to learners, teachers and ICT Technicians. Each school received 40 mobile Android tablets (30 learners and 10 teacher tablets), another 48 tablets were provided to the ICT Technicians ( 2 per school). Another technology infrastructure that was provided to each school was connectivity (Mi-fi hotspot device with a SIM card with $3 \mathrm{G}$ access), content servers (one for each school) and other electronic resources (e-textbooks on the servers, lesson plans for specific subjects when using mobile tablets, quizzes, tests and curriculum-related support material).

The TPD training commenced in the afternoons, for four (4) hours after school hours. TPD training was divided into six separate sessions of two consecutive days each. The TPD had two objectives: 1) To position the rural participating teacher for further lifelong learning, and 2) To change the classroom practice of the rural participating teachers to reflect an enhanced teaching and learning engagement through pedagogy for the information age.

The requirement for successful completion of TPD was that teachers needed to be selected by their school principal to attend the training; they had to be registered as a student for this training at the University of the Free State (UFS); they had to attend at least $90 \%$ of the classes (one class can be excused due to illness or a funeral); and they had to hand in and complete three reflective entry journals and two assignments. If they comply with these requirements teachers then received the credit-bearing Certificate in Teacher Professional Development for Digital Mobile Learning (CTPDDML) that is part of the introduction to the ICT module as part of the Advanced Certificates in Teaching at UFS. More detail on the teacher training is provded in another paper: Botha et al. (2017).

UFS trained two ICT Technicians per school (48 in total) in two sessions (one week each) at the DARD training facility (Free State Province). They each received certificates for each of the 6 modules they completed. The ICT Technicians were deployed to the school after the first training session and they were given specific roles and responsibilities to support the teachers (who already completed their training).

\section{METHODOLOGY}

Monitoring and evaluation were done through the application of developmental evaluation, which repositions evaluation as an internal, collaborative function and aligned best with the projects' Research and \& Development character. The purpose and objectives of the project, as well as its program components and activities, were conceptualized in two theories of change (implementation success and improved quality of teaching and learning) that frame the rationale for the project and its evaluation. The Funnell and Rogers (2011) definition of theory of change was applied which indicates that a program theory should contribute to a chain of intermediate results and finally to the intended or observed outcome.

In addition, the evaluation employed an array of mixed methods to address the two theories of change. A sequential, explanatory mixed methods approach was followed during the End-line survey where the use of both the qualitative and quantitative research methods in a singular study is applied (Creswell \& Clark, 2017). Quantitative data were analyzed using statistical and mathematical techniques (Principal Component 
Analysis/PCA and stepwise multiple regression analysis) in order to observe specific variables in a data set (Mouton, 2006). The thematic analysis of qualitative data (from one-to-one interviews was carried out using the Nvivo software version 11 (NVIVO, 2017). The data analysis for the quantitative phase of the survey was conducted using the SPSS version 24. The data analysis consisted of both descriptive and inferential statistics (associational and comparative).

\section{RESULTS}

The results will be provided by addressing the two theories of change: Implementation success and improved quality of teaching and learning (End-line survey). The results also address the research question posed in this paper under section 1: What evidence was found to indicate implementation success and improved quality of teaching and learning when mobile technology was used in training teachers in selected rural schools in South Africa?

\section{- Implementation success}

This was measured by tracking a) the consistent participation of the teachers in their TPD; b) tracking the technical training of the ICT Technicians to support teachers; c) identify how the project positively influenced the learners and finally d) how consistent the functionality of the technology was to support training and use of the mobile tablets.

a) Out of the 240 selected teachers, 56 dropped out (meaning 184 completed) mainly because they could not cope with doing this course on top of their teaching load. Upon completion of TPD, $67.7 \%$ of the final group of teachers complied with the accredited training criteria of the UFS. Five teachers have also enrolled for the Online Advanced Certificate in Teaching at UFS starting 2019 based on the successful completion of the TPD training. This is evidence of how this project definitely influenced the lifelong learning of the teachers at the 24 schools and influenced the rural education system of South Africa positively. Many teachers, principals, and learners expressed their gratitude to have been part of the project, and this is particularly the case in the deep rural areas where such opportunities are scarce. Their confidence levels using the technology grew, this encouraged the UFS team to continue, and to make sure that the program remains relevant. The human factor, where one pays attention to their joys and concerns, is an important factor to take note of. The statistical (both descriptive and inferential) evidence indicated that after the training of the teachers, $97 \%$ of the teachers indicated that they will continue to use ICT for teaching rather than traditional teaching and also $98 \%$ of the teachers indicated that they are willing to use ICT to teach. The teachers also indicated that for them the most outstanding benefit the training was to learn new teaching strategies.

b) The ICT Technician's technical training was successful as the average pass rate was $82 \%$. Their training and deployment were noted by most schools to be an advantage and huge support to assist them to integrate the technology into the teacher's teaching and learning practices. Twenty schools indicated that the trained ICT Technicians are consistently diligent and organized and support the schools by searching for Apps to support specific subjects and to organize a timetable to ensure each teacher can use the tablets for their classes during the week. They also support teachers in resolving technical problems. The existence of the Communities of Practice or Professional Learning Communities $\mathbf{7 9 . 5 \%}$ of the teachers indicated that they have established Communities of Practice with teachers during the end-line) that were formed amongst the teachers in each province and even across provinces is further evidence that the intervention was a success and has a possibility for sustainable use in future. Teachers use WhatsApp groups to share lesson ideas, especially in subjects like Mathematics and Biology. An important observation from UFS was that when young and motivated youth, who take an interest in building ICT skills of teachers at the school; teachers get motivated to make use of the technology in the classroom. Subsequently, integration occurs, which means that ICT integration becomes sustainable beyond formal training. This has an impact on educators and learners at the schools.

c) Learners positively affected by the project were $6895($ Boys $=3346$ Girls $=3549)$. The feedback of the teachers about the learners indicates that overall the discipline has improved, there are less absent learners, they find working with the technology very exciting and are more attentive in class. Teachers also indicated that for them $\mathbf{8 0 \%}$ of the learners are more participative in Grade 11 and the lowest mark in one of the Mathematic classes was only $\mathbf{4 0 \%}$ which was a huge improvement since the use of the tablets in the classroom. The coding of the feedback of the teachers revealed the following 
themes: ICT acceptance and use through collaborations with peers and teachers, positive change in classroom practice and positive attitude changes in learners. This is therefore evident that the ICT4E project has had a very positive influence on the behaviour, attendance, effort, and attention of the learners and has also supported the attainment of $21^{\text {st }}$-century skills in the learners.

d) Results on the functionality of the technology were that theft of tablets and tablets that freeze or do not want to operate were regarded as the biggest challenges that influenced the teachers' motivation to use the technology. However, most of the teachers did complete the course successfully and were satisfied and grateful for the provided technology and training. Another major findings was that if principals support the project then everyone is eager to use the technologies. Three schools also reported that they will get their own Internet and buy more tablets from their own funds to ensure the sustainability of the project.

- The measurement of the improved quality of teaching and learning

This was done by doing a baseline and End-line assessment (survey questionnaire). This paper will only provide some significant End-line results (descriptive and inferential statistical analysis).

Demographics: A quarter $(26.1 \%$ ) of the participants was male and $73.9 \%$ female; the ages ranged from 27 to 59 years and the average age of the group of teachers was 45.5 years; more than three-quarters of the teachers $(77.3 \%)$ had a Bachelor's or higher degree. The home language of $23 \%$ of the teachers was Afrikaans, $20 \%$ Sepedi, $18 \%$ isiZulu, $14 \%$ isiXhosa and $13 \%$ Setswana.

After the TPD training inferential statistics (Pearson correlation coefficient that measures the strength of a linear association between two variables and is denoted by $r$ ), indicated that the three highest statistically significant correlated items with 'Extent of training' were:

- 'Basic usage of ICTs in education', $r=.823, \mathrm{p}<.01$;

- 'Integrating ICT in the curriculum using the World Wide Web', $r=.652, p<.01$;

- 'Integrating ICT in classroom projects', $r=.617, \mathrm{p}<.01$; and

The three highest statistically significant correlated items with the teachers' 'Attitudes towards technology' were:

- 'The use of the tablet computer as a learning tool excites me', $\mathrm{r}=.721, \mathrm{p}<.01$;

- 'The tablet computer helps students understand concepts in more effective ways', $r=.711, p<.01$;

- 'The tablet computer helps educators to teach in more effective ways', $\mathrm{r}=.709, \mathrm{p}<.01$; and

Regarding the teachers digital literacy and acceptance levels of ICT the teachers indicated that they feel they have good ICT skills $(r=.759, \mathrm{p}<.01)$ and that they are confident to obtain information from the Web to support their teaching and learning activities in the classroom $(r=.735, p<.01)$.

Three multiple regression analyses were conducted. The first analysis used 'Self-confidence in integrating ICT', the second analysis used the 'Level of digital literacy' of teachers and the third analysis used 'Attitudes towards technology' as dependent variables. Each of these scales was separately used as a dependent variable in a stepwise multiple regression analysis with the remaining scales as independent variables. Before the Stepwise regression analyses were performed, a bivariate correlation analysis was conducted to establish the strength of the bivariate associations.

Table 1. Bivariate correlation matrix of developed scales for the survey population

\begin{tabular}{|c|c|c|c|c|c|c|}
\hline Standardized scales & 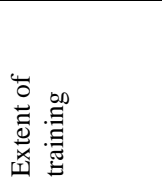 & 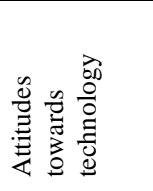 & 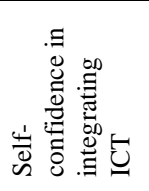 & 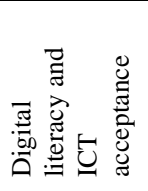 & 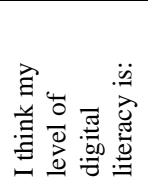 & 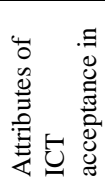 \\
\hline Extent of training & - & & & & & \\
\hline $\begin{array}{l}\text { Self-confidence in integrating } \\
\text { ICT }\end{array}$ & 0.152 & $\begin{array}{l}.675 \\
* *\end{array}$ & - & & & \\
\hline $\begin{array}{l}\text { Digital literacy and } \\
\text { acceptance }\end{array}$ & $\begin{array}{l}0.280 \\
* *\end{array}$ & $\begin{array}{l}.407 \\
* *\end{array}$ & $\begin{array}{l}.564 \\
* *\end{array}$ & - & & \\
\hline $\begin{array}{l}\text { I think my level of digital literacy } \\
\text { is }\end{array}$ & 0.066 & $\begin{array}{l}.405 \\
* *\end{array}$ & $\begin{array}{l}.395 \\
* *\end{array}$ & $\begin{array}{l}.562 \\
* *\end{array}$ & - & \\
\hline
\end{tabular}


The following statistically significant correlations were highly correlated:

- 'Self-confidence in integrating ICT' and 'Attributes of ICT acceptance in teaching', $r=.715, p<.01$.

- 'Self-confidence in integrating ICT' and 'Attitudes towards technology', $r=.675, p<.01$.

- 'Digital literacy and ICT acceptance' and 'Attributes of ICT acceptance in teaching', $r=.600, p<.01$.

- 'Self-confidence in integrating ICT' and 'Digital literacy and ICT acceptance', $r=.564, p<.01$.

At the end of the training, $67 \%$ of teachers indicated that they have developed digital content and using Apps in class to teach ( $72 \%$ ). In the end-line, $100 \%$ of the teachers indicated that 'The tablet computer helps the teacher to teach in more effective ways'.

The three highest statistically significant correlated items with 'Attributes of ICT acceptance in teaching' after the teacher's training was completed, were as follows:

- 'Using ICT will enable me to exercise my teaching work easier', $r=.818, p<.01$;

- 'Using ICT will enable me to positively teach more learners', $r=.811, p<.01$;

- 'My intentions are to continue using ICT for teaching rather than traditional teaching, $r=.726$, $\mathrm{p}<.01$; and

The $\mathrm{r}=.818$ is a significant indication that after the training the teachers feel that using ICT will enable them to exercise their teaching easier and they feel ICT will enable them to teach more learners positively and that they want to continue to use ICT for teaching rather than traditional teaching. This is also the first known project (that CSIR researchers are aware of) in South Africa that has statistical evidence to prove its success.

\section{CONCLUSIONS AND RECOMMENDATIONS}

ICT in Education initiatives notoriously falter in their implementation when unique obstacles to uptake are not addressed. One of this project's highest level outcomes was to avoid implementation failure precisely by providing for these obstacles in its design, and in so doing modelling implementation success. To assess implementation success, the evaluation posed 3 questions: 1) Were the program components, and the project overall, feasible to implement? 2) Which factors support, inhibit or prevent implementation (theft, demotivated teachers and teachers not coping seem to be the biggest contributors)? And 3) What are the lessons learned about the implementation of this project that should be transferred to others (below these are provided)?

The implementation experience of ICT4E is instructive in distinguishing between factors inhibiting successful implementation that are within the control of the project, and those inhibiting factors external to it. A crucial inhibiting factor is the state of technology infrastructure in rural areas. Even with a project design that assumes full responsibility for installing a complete technology ecosystem, some functionality, especially electricity, remains independent of project efforts.

Despite a comprehensive design that accounted for the common obstacles within its control, ICT4E's implementation was nevertheless tested, with mixed results. Particularly challenging was the availability of the ICT Technicians, technical problems with the tablets and theft. The level of committed collaboration also varied from school to school. While there is evidence of the use of technology by teachers in the classroom the quality and relevance of teaching materials employed for this (which the content servers were expected to facilitate) is unclear.

The thorough and inspiring teacher and ICT Technicians training and deployment were enabling factors, which was evident in the fact that many teachers kept using technology and teaching practices. A system-wide approach - parents, administration and District officials (especially subject advisors) - is required to create a conducive environment for the use of technology as a conventional teaching practice to be adopted widely.

A success story is the teacher training and the apparent changes in teaching practice as well as the teacher's feedback on the effect the project has had on the attitudes, discipline, and attendance of learners. Their marks improved in some subjects where they are using mobile tablets, especially at the secondary school level (Grade 8-12).

The long term sustainability will only become apparent over time. A key issue is what are the components of an enabling environment? Ongoing evaluation is therefore required to develop recommendations for supporting teachers and schools. To sustain technology in future the identified barriers in the whole system (a project at District/Circuit level and the supporting systems of the department) need to be addressed. The lack 
of sufficient e-content to support all subjects at all levels and in the various South African languages was identified as a significant need.

The lessons learned in ICT4E should be used by all provincial Departments of Education to guide the design and implementation of "teaching with technology" strategies.

The main lessons learned were:

- If there is a lack of commitment from the principal then teachers are not eager to participate or to integrate mobile technology in their classrooms;

- To import international e-content sources does not work as it has to be contextualized;

- The lack of reliable and fast Internet in South Africa, especially in resource constraint/rural areas, hinders the use of technology - this is coupled with high data prices;

- Sustainability is a challenge as once a project is done usage of mobile technology fades. This has to be part of the exit strategy from the beginning and involvement from the district side is crucial;

- Security of devices is a concern in most projects as devices are stolen and not replaced (when outdated);

- Technical support during and after implementation is important;

- Change management should be a priority since the inception of any mobile technology project;

- Teachers need to be empowered through ICT integration courses and refreshment courses at least once a year;

- Establishing collaborations and networks amongst teachers to share content can influence sustainability.

\section{ACKNOWLEDGMENT}

This paper acknowledges the funding support of the National Research Foundation (NRF) in South Africa with grant number: 112252. It also acknowledges the DRDLR ICT4E Project which is funded by the DARD and where the UFS provides the training of the teachers in every school.

\section{REFERENCES}

Adukaite, A., Van Zyl, I., Er, Ş. \& Cantoni, L. 2017. Teacher perceptions on the use of digital gamified learning in tourism education: The case of South African secondary schools. Computers \& Education, 111:172-190.

Ally, M. 2009. Mobile learning: Transforming the delivery of education and training. Edmonton: AU Press.

Bates, T., Swennen, A. \& Jones, K. 2014. The professional development of teacher educators. Routledge.

Botha, A. \& Herselman, M. 2018. Teachers become cocreators through participation in a teacher professional development (TPD) course in a resource constraint environment in South Africa. The Electronic Journal of Information Systems in Developing Countries, 84(1):e12007.

Botha, A., Herselman, M., Musgrave, S. \& Jaeschke, G. 2017. Dimensional evaluation of a rural mobile learning teacher professional development curriculum. The Institute for Science and Technology Education (ISTE). Kruger Park. https://researchspace.csir.co.za/dspace/handle/10204/10048.

Chiu, T.K. \& Churchill, D. 2016. Adoption of mobile devices in teaching: Changes in teacher beliefs, attitudes and anxiety. Interactive Learning Environments, 24(2):317-327.

Creswell, J.W. \& Clark, V.L.P. 2017. Designing and conducting mixed methods research. Sage publications.

Dagdilelis, V. 2018. Preparing teachers for the use of digital technologies in their teaching practice. Research in Social Sciences and Technology, 3(1):109-121.

Department of Basic Education. 2004. White paper on E-Education: Transforming learning and teaching through information and communication technologies. [Online]. Available: http://www.education.gpg.gov.za/Legislation/White\%20paper\%207\%20on\%20e-Education.pdf [Accessed.

Dlamini, S. \& Van Der Vyver, A. 2019. A Qualitative Analysis of an E-education Initiative in Deep Rural Schools in South Africa: A Need to Build Resilience. Cham: Springer International Publishing.

Ekanayake, S.Y. \& Wishart, J. 2014. Integrating mobile phones into teaching and learning: A case study of teacher training through professional development workshops. British Journal of Educational Technology:n/a-n/a. 
Fu, Q.-K. \& Hwang, G.-J. 2018. Trends in mobile technology-supported collaborative learning: A systematic review of journal publications from 2007 to 2016. Computers \& Education.

Funnell, S.C. \& Rogers, P.J. 2011. Purposeful program theory: Effective use of theories of change and logic models. John Wiley \& Sons.

Herselman, M., Botha, A. \& Maremi, K. 2019. Evaluating a mobile tablet project in rural South Africa against criteria to comply with being an innovative educational ecosystem. 3rd International Conference on Education and Multimedia Technology. . Nagoya, Japan

Hwang, G.-J., Chu, H.-C. \& Lai, C.-L. 2017. Prepare your own device and determination (PYOD): a successfully promoted mobile learning mode in Taiwan. International Journal of Mobile Learning and Organisation, 11(2):87-107.

Jantjies, M. \& Joy, M. 2016. Lessons learnt from teachers' perspectives on mobile learning in South Africa with cultural and linguistic constraints. South African Journal of Education, 36(3):1-10.

Karam, R., Straus, S.G., Byers, A., Kase, C.A. \& Cefalu, M. 2018. The role of online communities of practice in promoting sociotechnical capital among science teachers. Educational Technology Research and Development, 66(2):215-245.

Kotzé, T., Van Der Westhuizen, M. \& Barnard, E. 2017. Teaching strategies to support isiXhosa learners who receive education in a second/third language. South African Journal of Education, 37(3):1-12.

Mabila, J., Van Biljon, J. \& Herselman, M. 2017. A sustainability framework for mobile technology integration in schools: The case of resource-constrained environments in South Africa.

Mouton, J. 2006. How to Succeed in Your Master's and Doctoral Studies: A South African Guide and Resource Book. Pretoria: Van Schaik.

Naiman, L. 2016. Design thinking as a strategy for innovation.: Creativity at work. [Online]. Available: http://www.creativityatwork.com/design-thinking-strategy-for-innovation/ [Accessed.

National Planning Commission. 2012. National Development Plan 2030: Our future-make it work. Presidency of South Africa, Pretoria, 1.

Nvivo. 2017. Homepage. [Online]. Available: https://www.qsrinternational.com/ [Accessed 31 January].

Ramorola, M.Z. 2018. Transforming teaching and learning through technology integration.

Rikkerink, M., Verbeeten, H., Simons, R.-J. \& Ritzen, H. 2016. A new model of educational innovation: Exploring the nexus of organizational learning, distributed leadership, and digital technologies. Journal of Educational Change, 17(2):223-249.

Scherer, R., Siddiq, F. \& Tondeur, J. 2019. The technology acceptance model (TAM): a meta-analytic structural equation modeling approach to explaining teachers' adoption of digital technology in education. Computers \& Education, 128:13-35.

Teo, T., Lee, C.B. \& Chai, C.S. 2008. Understanding pre-service teachers' computer attitudes: applying and extending the technology acceptance model. Journal of Computer Assisted Learning, 24:128-143.

Terhoven, R. \& Fataar, A. 2018. The role of leadership practices in establishing a curriculum policy platform at working-class schools. South African Journal of Education, 38(2):1-10.

Vandeyar, T. 2010. The appropriation of education policy on information and communication technology in South African schools. Pretoria, South Africa: University of Pretoria.

Vosloo, S. 2011. The teacher crises, UNESCO Mobile learning week. UNESCO, Paris. 